\title{
BREVE REVISÃO DE MÉTODOS DE DETERMINAÇÃO DE RESÍDUOS DO HERBICIDA ÁCIDO 2,4- DICLOROFENOXIACÉTICO (2,4-D)
}

Ozelito Possidônio de Amarante Júnior*, Teresa Cristina Rodrigues dos Santos e Gilvanda Silva Nunes

Departamento de Tecnologia Química, Universidade Federal do Maranhão, Av. dos Portugueses, s/n, 65080-040 São Luís - MA Maria Lúcia Ribeiro

Instituto de Química, Universidade Estadual Paulista "Júlio de Mesquita Filho”, Rua Prof. Francisco Degni, s/n, 14800-900 Araraquara - SP

CONCISE REVISION OF METHODS FOR DETERMINATION OF THE HERBICIDE DICHLOROPHENOXYACETIC ACID (2,4-D). This paper supplies a revision about the main techniques of extraction, clean-up and pre-concentration of the herbicide 2,4-dichlorophenoxyacetic acid (2,4-D) in water and soil samples, as well as chromatographic methods and immune assays for its identification and quantification.

Keywords: 2,4-D; chromatography; immune assays.

\section{INTRODUÇÃO}

Os herbicidas ácidos são uma importante classe de pesticidas, dos quais se destaca o ácido 2,4-diclorofenoxiacético (2,4-D), por sua ampla utilização em todo o mundo ${ }^{1}$. Este composto tem sido usado no controle de uma variedade de ervas daninhas, em culturas de cereais, cana-de-açúcar, pomares e em controle florestal ${ }^{2}$. Não é recente a larga aplicação do 2,4-D, pertencente à classe dos ácidos fenoxiacéticos. Desde a guerra do Vietnã, quando foi usado pela força aérea norte-americana como agente desfolhante, junto com o ácido 2,4,5-triclorofenoxiacético (2,4,5-T) e o pentaclorofenol (PCF), formando o "agente laranja", o 2,4-D vem substituindo a capina manual e mecânica, diminuindo a mão-de-obra e resultando no aumento da produtividade agrícola ${ }^{3}$. O 2,4-D é classificado pela Agência Nacional de Vigilância Sanitária (ANVISA) ${ }^{4}$ como um herbicida hormonal de toxicidade II. Igual classificação é dada pela Organização Mundial de Saúde (World Health Organization - WHO) e pela Agência de Proteção Ambiental dos Estados Unidos (United StatesEnvironmental Protection Agency - US-EPA) $)^{5}$. 2,4-D é comercializado em formulações de sais, amina e éster, sendo de ação pósemergente ${ }^{1}$. Embora o herbicida tenha sido sintetizado em 1942 e já comercializado na década de 40, existem, ainda hoje, lacunas de informações relativas aos efeitos à saúde humana e riscos ao ambiente. Por ser altamente seletivo e sistêmico, 2,4-D é transportado pela planta, sendo acumulado nos tecidos em crescimento das raízes, agindo por inibição do crescimento das ervas ${ }^{6}$. O 2,4-diclorofenol (2,4-DCF) é o principal produto de degradação do herbicida 2,4-D, como mostrado na Figura 1.

Existem vários métodos de determinação do 2,4-D em solo, água,

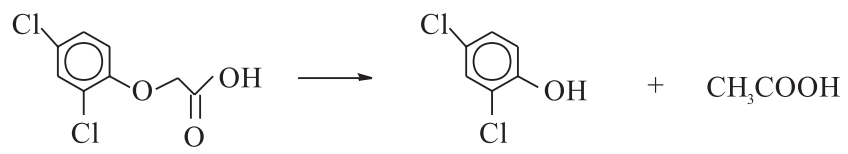

Figura 1. 2,4-D e seu principal produto de degradação, 2,4-diclorofenol

*e-mail: ozelito@terra.com.br cereais, frutas e outras matrizes ${ }^{7}$, empregando imunoensaios ${ }^{8,9}$, eletroforese ${ }^{10}$, cromatografia gasosa $(\mathrm{CG})^{1}$ e cromatografia líquida $(\mathrm{CL})^{7}$. Os métodos baseados em CG com detecção por captura de elétrons (CG/DCE) são os mais utilizados, visto que apresentam elevada sensibilidade, porém exigem uma etapa de derivação dada a elevada polaridade do composto ${ }^{11}$. Os métodos de análise do 2,4-D por CL costumam ser mais simples e rápidos, se comparados com sua determinação por $\mathrm{CG}^{12}$. Vários métodos baseados em CL determinam simultaneamente o herbicida e seu principal produto de degradação, o 2,4-DCF, em amostras de água ${ }^{13}$, embora apenas dois métodos sejam citados para esta análise simultânea em amostras de solo: (i) o primeiro utilizando compostos radiomarcados, apresentado pela Agência de Proteção Ambiental dos Estados Unidos (USEPA) e (ii) o segundo consistindo de uma simples extração seguida da análise cromatográfica com detecção por $U^{14}$.

Devido à sua ampla utilização, o conhecimento e a avaliação dos principais métodos de determinação do 2,4-D em amostras ambientais são de fundamental importância. Assim, este trabalho discute os métodos mais usados na análise deste herbicida.

\section{MÉTODOS DE EXTRAÇÃO E PRÉ-CONCENTRAÇÃO}

\section{Amostras de solo}

Conforme se observa na Tabela 1, os métodos mais descritos na literatura para extração de 2,4-D em amostras de solo são baseados em extração com diclorometano (DCM), acidificando-se previamente a amostra e procedendo à purificação por extração líquido-líquido, onde a primeira etapa é realizada com solução alcalina, e a segunda, após nova acidificação, com fase orgânica (DCM) ${ }^{15}$. Recuperações entre $87-90 \%$ têm sido obtidas.

Outro solvente utilizado para extrair 2,4-D de solos é o éter dietílico, empregado também após a acidificação da amostra, efetuando-se a extração por três vezes. Neste estudo, recuperações em torno de $87 \%$ foram obtidas ${ }^{16}$. Entretanto, ainda é comum o uso de sistema Soxhlet para extração de contaminantes orgânicos do solo ${ }^{17}$, incluindo-se os pesticidas. Soxhlet pode ser usado com o sistema de solventes hexano/acetona $(1: 1)^{18}$, ou, ainda, com água/metanol (25:75), utilizando-se, também, extração com ultra-som ${ }^{14,19}$. 
Tabela 1. Extração de 2,4-D em amostras de água e solo

\begin{tabular}{|c|c|c|c|c|}
\hline Amostra & Extração & Purificação & Recuperação & Ref. \\
\hline \multirow[t]{5}{*}{ Solo } & $\operatorname{EFSC}\left(\mathrm{CO}_{2}\right)$ & & & 15 \\
\hline & $\begin{array}{l}\mathrm{DCM}+\text { água (acidificada com ácido } \\
\text { sulfúrico } 9 \mathrm{M} \text { a } \mathrm{pH} 1,2 \text { ) }\end{array}$ & $\begin{array}{l}\text { Decantação } \\
\text { Filtração (papel e celite) } \\
\text { Extração com } \mathrm{NaOH} \\
\text { Acidificação }\left(\mathrm{H}_{2} \mathrm{SO}_{4} 9 \mathrm{M}\right) \\
\text { Extração com } \mathrm{DCM}^{-} \\
\text {Filtração em } \mathrm{NaSO}_{4} \text { anidro } \\
\text { Secagem }\end{array}$ & $87-90 \%(2,4-\mathrm{D})$ & 15 \\
\hline & $\begin{array}{l}\text { Acidificação com } \mathrm{H}_{2} \mathrm{SO}_{4}(\mathrm{pH} 1,0), \\
\text { seguido de } 3 \times 50 \mathrm{~mL} \text { de éter dietílico }\end{array}$ & & $\sim 87 \%$ & 16 \\
\hline & $\begin{array}{l}\text { Soxhlet }\left(\mathrm{H}_{2} \mathrm{O} / \text { Metanol, } 25: 75\right) \text { ou ultra-som } \\
\text { Filtração }\end{array}$ & & & 19 \\
\hline & $\begin{array}{l}\text { Acidificação pH } 2 \text { e secagem, } \\
\text { extração por } 8 \text { h em Soxhlet com } \\
\text { hexano:acetona ( } 1: 1)\end{array}$ & & & 18 \\
\hline \multirow[t]{9}{*}{$\overline{\text { Água }}$} & EFS (carbono grafítico) & & $97-98 \%$ & 20 \\
\hline & EFS (carbono grafítico) & & $\sim 98 \%$ & 21 \\
\hline & EFS (C18) & & & 19 \\
\hline & EFS (C18) após ajuste de $\mathrm{pH}$ & & $\sim 89,3 \%$ & 22 \\
\hline & EFS (C18) (“on line”) & & $90 \%$ & 23 \\
\hline & EFS (estirenodivinilbenzeno) (“on line") & & $90,7-106,9 \%$ & 13 \\
\hline & Resina de adsorção & & $\sim 103 \%$ & 24 \\
\hline & DCM após acidificação & & $\sim 88,1 \%$ & 24 \\
\hline & n-heptano & Separação por membrana (“on line”) & & 25 \\
\hline
\end{tabular}

EFSC: Extração com Fluido Supercrítico; EFS: Extração em Fase Sólida; DCM: Diclorometano

Outra alternativa é a extração do 2,4-D por fluido supercrítico (EFSC), utilizando $\mathrm{CO}_{2}$ modificado com ácido benzóico/metanol ${ }^{15}$.

\section{Amostras de água}

É prática comum utilizar processos de extração líquido-líquido para extrair 2,4-D, por exemplo, com diclorometano (DCM) após acidificação da amostra, em procedimento similar ao realizado com amostras de solo. Recuperações entre $90-115 \%$ foram obtidas ${ }^{24}$. Estudo de extração com n-heptano ${ }^{25}$, procedendo etapa de purificação com separação por membrana ("on-line") também foi realizado. No entanto, processos de extração líquido-líquido têm a desvantagem de usar elevados volumes de solventes orgânicos, além de favorecer a perda do analito pelo manuseio em várias etapas (extração, separação das fases, secagem, redissolução, entre outras).

2,4-D pode, também, ser extraído de amostras de água por Extração em Fase Sólida (EFS) utilizando carbono grafítico ${ }^{20,21}$, ou cartucho $\mathrm{C} 18$, sem correção de $\mathrm{pH}^{19}$ ou com ajuste de $\mathrm{pH}^{22}$, podendo-se proceder a extração "on-line" 23 , com as vantagens adicionais de reunir, em uma única etapa, a extração, purificação e pré-concentração. Entretanto, segundo Santos e colaboradores ${ }^{13}$, a utilização de cartuchos recheados com material polimérico fornece recuperações superiores àquelas obtidas com $\mathrm{C} 18$, considerando-se a natureza polar da molécula do herbicida. Neste caso, a recuperação do composto e seu produto de degradação, em pré-colunas empacotadas com copolímero estirenodivinilbenzeno, forneceu recuperações entre 91-
107\%. Resinas de adsorção costumam, também, ser usadas, com recuperações entre $79-96 \%{ }^{24}$.

Técnicas recentes de pré-tratamento de amostras têm o intuito de separar compostos com propriedades muito parecidas, uma vez que estas substâncias tendem a ser co-extraídas por métodos convencionais de extração líquido-líquido ou EFS. Compostos com estruturas similares, além de serem extraídos juntas, podem ser coeluídos, necessitando-se, assim, de técnicas de pré-tratamento que consigam separá-los previamente. Com este objetivo, pode-se utilizar a técnica de isotacoforese capilar. Estudo utilizando esta técnica apresentou recuperações em torno de $99 \%$ para 2,4-D ${ }^{26}$.

\section{MÉTODOS DE ANÁLISE}

\section{Determinação cromatográfica}

$\mathrm{Na}$ análise do 2,4-D e do seu principal produto de degradação, 2,4-DCF, as técnicas cromatográficas são as mais utilizadas. Entre os métodos empregados, destacam-se os baseados em CG, empregando detecção por captura de elétrons $(\mathrm{DCE})^{1}$ devido à sua elevada sensibilidade, embora Hong e colaboradores citem este detector como pouco sensível para o herbicida ${ }^{16}$. A detecção por espectroscopia de massas (EM) é uma alternativa que alia sensibilidade à elevada seletividade, sendo possível obter fragmentogramas para cada pico do cromatograma, o que confirma a identificação do composto estudado $^{11}$. Ambos os métodos, porém, necessitam de prévia derivação, 
Tabela 2. Determinação de 2,4-D por cromatografia

\begin{tabular}{|c|c|c|c|}
\hline Técnica & Análise & LD/LQ & Ref. \\
\hline \multirow[t]{8}{*}{ CLAE } & $\begin{array}{l}\text { Coluna: LiChrocart com LiChrospher 60RP. } \\
\text { FM: (A) acetonitrila e (B) tampão formiato de amônio } 5 \mathrm{mmol} \mathrm{L}^{-1}(\mathrm{pH} 3) \text { com gradiente } \\
\text { Fluxo: } 0,9 \mathrm{~mL} / \mathrm{min} \\
\text { DCD }(230 \mathrm{~nm}) \text { e EM }\end{array}$ & $\mathrm{LD}=0,02 \mu \mathrm{g} \mathrm{L}^{-1}$ & 13 \\
\hline & $\begin{array}{l}\text { Coluna: C-18 } \\
\text { FM: TFA } 0,05 \% \text { em água e acetonitrila } 0,025 \% \text { de TFA (60:40) linearmente até } \\
67 \% \text { de acetonitrila em } 20 \mathrm{~min} \\
\text { Fluxo: } 1,5 \mathrm{~mL} / \mathrm{min} \\
\text { Detecção: UV } 230 \mathrm{~nm}\end{array}$ & $\mathrm{LD}=0,03 \mu \mathrm{g} \mathrm{L}^{-1}$ & 20 \\
\hline & $\begin{array}{l}\text { Coluna: C18 } \\
\text { FM: (A) Metanol e (B) ácido perclórico (Gradiente) } \\
\text { Fluxo } 1 \mathrm{~mL} / \mathrm{min} \\
\text { Detecção: UV }\end{array}$ & $\mathrm{LD}=15 \mathrm{ng} \mathrm{L}^{-1}$ & 23 \\
\hline & $\begin{array}{l}\text { Coluna: C18 } \\
\text { FM: (A) Metanol /água/ácido acético (145/130/15) e (B) água } \\
\text { Detecção = } 280 \mathrm{~nm}\end{array}$ & $\begin{array}{l}1 \mathrm{ppm}-1 \mathrm{ppb} \\
\sim 1 \mathrm{ppb}\end{array}$ & 24 \\
\hline & $\begin{array}{l}\text { Coluna: C18 } \\
\text { FM: Metanol com } 1,7 \mathrm{mg} \mathrm{L}^{-1} \text { de PAA e ácido acético } 1 \% \text { (70:30) ou } \\
\text { Metanol/ácido acético } 1 \%(68: 32) \\
\text { Detecção: EM }\end{array}$ & $\mathrm{LD}=1,1 \mu \mathrm{g} \mathrm{\textrm {L } ^ { - 1 }}$ & 22 \\
\hline & $\begin{array}{l}\text { Coluna: C18 } \\
\text { FM: (A) Metanol:acetonitrila (82:18) e (B) água:TFA }(0,17 \%) \\
\text { Detecção: UV }\end{array}$ & $\begin{array}{l}\mathrm{LQ}=5 \times \mathrm{LD} \\
\mathrm{LD}=6,8 \mathrm{ng} \mathrm{L}^{-1}\end{array}$ & 21 \\
\hline & $\begin{array}{l}\text { Coluna: C18 } \\
\text { Detecção: UV e EM }\end{array}$ & $\begin{array}{l}\mathrm{LD}=200 \mathrm{pg}(\mathrm{UV}) \\
\mathrm{LD}=20 \mathrm{pg}(\mathrm{EM})\end{array}$ & 25 \\
\hline & $\begin{array}{l}\text { Coluna: C18 } \\
\text { FM: Metanol/solução tampão (pH 3) } \\
\text { Detecção: UV (240 nm) }\end{array}$ & & 27 \\
\hline \multirow[t]{10}{*}{ CG } & $\begin{array}{l}\text { Derivatização com brometo de pentafluorbenzil } \\
\text { Clean up: florisil } \\
\text { Coluna: DB-1 (com gradiente de temperatura) } \\
\mathrm{N}_{2}: 13 \mathrm{~mL} / \mathrm{min} \\
\text { Detecção: DCE }\end{array}$ & $\mathrm{LQ}=0,01-0,17 \mathrm{ppm}$ & 1 \\
\hline & $\begin{array}{l}\text { Coluna: sílica fundida BP-1 (gradiente de temperatura) } \\
\text { Gás de arraste: He (10 psig) } \\
\text { Detecção: EM }\end{array}$ & $\begin{array}{l}\mathrm{LD}=0,01 \mu \mathrm{g} / \mathrm{g} \\
\text { (podendo ser melhorado } \\
\text { para } 0,005 \mu \mathrm{g} / \mathrm{g} \text { ) }\end{array}$ & 15 \\
\hline & $\begin{array}{l}\text { Gás de arraste: He (Argônio-Metano como make-up) } \\
\text { Detecção: DCE } \\
\text { Gás de arraste: He } \\
\text { Detecção: EM }\end{array}$ & $\mathrm{LD}=0,5 \mu \mathrm{g} \mathrm{\textrm {L } ^ { - 1 }}$ & 16 \\
\hline & $\begin{array}{l}\text { Derivatização com } \mathrm{BF}_{3}-\mathrm{MeOH} \\
\text { Detecção: DCE* }\end{array}$ & $\mathrm{LD}=0,01 \mathrm{mg} \mathrm{Kg}^{-1}$ & 7 \\
\hline & $\begin{array}{l}\text { Derivatização com } \mathrm{BF}_{3}-\mathrm{MeOH} \\
\text { Detecção: } \mathrm{EM}^{*}\end{array}$ & $\mathrm{LD}=0,1 \mathrm{mg} \mathrm{Kg}^{-1}$ & \\
\hline & $\begin{array}{l}\text { Derivatização com } \mathrm{BCl}_{3} \text {-2-cloroetanol } \\
\text { Detecção: DCE* }\end{array}$ & $\mathrm{LD}=0,2 \mathrm{mg} \mathrm{Kg}^{-1}$ & \\
\hline & $\begin{array}{l}\text { Derivatização com diazometano } \\
\text { Detecção: DCE* }\end{array}$ & $\mathrm{LD}=0,1 \mathrm{mg} \mathrm{Kg}^{-1}$ & \\
\hline & $\begin{array}{l}\text { Derivatização com diazometano } \\
\text { Detecção: DCE* }\end{array}$ & $\mathrm{LD}=10 \mathrm{mg} \mathrm{Kg}^{-1}$ & \\
\hline & $\begin{array}{l}\text { Derivatização com diazometano } \\
\text { Detecção: DCE* }\end{array}$ & $\mathrm{LD}=0,05(0,02) \mathrm{mg} \mathrm{Kg}^{-1}$ & \\
\hline & $\begin{array}{l}\text { Derivatização com diazometano e BrI } \\
\text { Detecção: DCE* }\end{array}$ & $\mathrm{LD}=0,05 \mathrm{mg} \mathrm{Kg}^{-1}$ & \\
\hline
\end{tabular}

\footnotetext{
* Método empregado por autores diferentes, citados na referência 7
} 
com formação de composto volátil. Neste sentido, pode-se efetuar esterificação ${ }^{11}$ utilizando-se solução de ácido sulfúrico e trifluoroetanol (TFE) ${ }^{16}$. Derivações podem também ser efetuadas com brometo de pentafluorbenzil ${ }^{1}$, com $\mathrm{BF}_{3} /$ metanol, $\mathrm{BCl}_{3} / 2$-cloroetanol, diazometano ou com BrI/diazometano?

Cromatografia de fluido supercrítico tem a vantagem de não necessitar de derivação, além de se obterem boas recuperações e elevada sensibilidade. Neste método, pode-se utilizar coluna de sílica fundida com DB-1, usando como fluido o $\mathrm{CO}_{2}$, com programação de pressão e detecção por "mobilidade iônica" 18 .

Métodos baseados em cromatografia líquida de alta eficiência (CLAE) são menos laboriosos que os por CG, uma vez que não necessitam de derivação, embora sejam menos sensíveis. Para estes métodos, os detectores mais usados são os baseados em absorção na região do Ultravioleta (UV), em $230 \mathrm{~nm}^{14,22}, 240 \mathrm{~nm}^{27}$ ou $280 \mathrm{~nm}^{24}$. A maior absorção de UV por 2,4-D tem sido registrada em 229 e 283 $\mathrm{nm}^{28}$. Pode-se utilizar, ainda, detector de conjunto de diodos (DCD), que proporciona espectros na região do $\mathrm{UV} \mathrm{VIS}^{13}$. Realiza-se a detecção, também, por EM²2.

Utilizando-se esta técnica, pode-se ainda empregar colunas baseadas em polímero de molécula impressa. No caso, o material polimérico desenvolvido é capaz de reconhecer uma molécula ou grupos de moléculas, podendo empregá-lo na etapa de extração (EFS) ou na etapa analítica. O polímero é sintetizado, interagindo-se a molécula de interesse (molécula molde), presente em uma solução padrão, com monômeros contendo grupos funcionais. Após a interação, realiza-se a polimerização, adicionando-se monômeros que servirão para a estrutura de sustentação do polímero. Geralmente, incide-se UV para efetuar as ligações entre os monômeros funcionais e os estruturais. Obtém-se, deste modo, polímero que reconhece a "molécula molde" dentro de uma matriz ${ }^{29}$. Este método foi empregado para análise do ácido 2,4,5-triclorofenoxiacético (2,4,5-T), no qual se obteve um material polimérico capaz de determinar $2,4,5$ $\mathrm{T}$ e 2,4-D, utilizando-se $\mathrm{CL}^{30}$.

Os principais métodos de análise cromatográfica de 2,4-D, citados na literatura, são resumidamente apresentados na Tabela 2.

\section{ANÁLISE ENVOLVENDO TÉCNICAS BIOANALÍTICAS}

\section{Biossensores e imunoensaios para análise de pesticidas}

O biossensor é uma ferramenta analítica que pode ser definida como a combinação de um elemento de reconhecimento biológico (como por exemplo enzima, célula, organela, anticorpo, entre outros) e um transdutor físico, em íntimo contato entre eles. O papel do transdutor é relacionar a concentração de um determinado analito a uma propriedade química ou física, que será seqüencialmente detectada, convertida em um sinal elétrico/óptico, que é amplificado ${ }^{31-34}$ (Figura 2). Muitos princípios de transdução estão sendo explorados, incluindo fotometria, fluorimetria e quimioluminescência, fibras ópticas, sensores piezoelétricos, além dos eletrodos potenciométricos e amperométricos. Em geral, as medidas são feitas baseando-se no consumo ou na produção de algum composto que participa de uma reação bioquímica. Exemplos de reconhecimentos bioquímicos e transdutores são fornecidos na Tabela 3 .

De um modo geral, os biossensores têm sido desenvolvidos e aplicados às análises clínicas, ambientais e de alimentos ${ }^{33-37}$. Na atualidade, os projetos eletroquímicos têm sido mais explorados devido à sua simplicidade e à possibilidade de se construírem biossensores de baixo custo, quando as enzimas são utilizadas como elementos de bio-reconhecimento. As características e vantagens desses tipos de biossensores podem ser assim resumidas: simplicidade, baixo custo da instrumentação, treinamento simples de pessoal, respostas rápi-
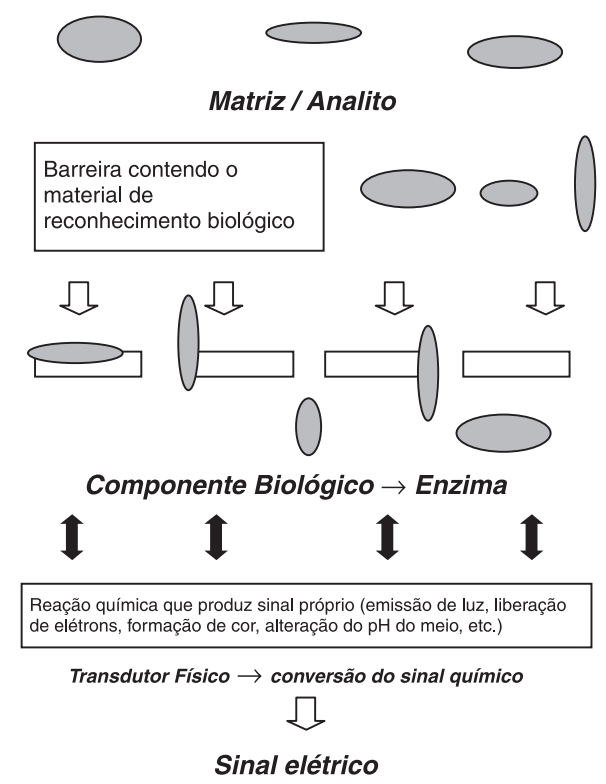

Figura 2. Estratégia analítica esquematizada de um biossensor. $O$ analito interage com o elemento de bio-reconhecimento e atravessa uma membrana; o elemento biológico é, em geral, uma enzima, ou algum tipo de microorganismo, que vai reagir com seu substrato e dar início a uma reação química, cujo sinal será monitorado e convertido em um sinal elétrico ou óptico quantificável

Tabela 3. Principais sistemas de bio-reconhecimento/transdução utilizados na construção dos biossensores

\begin{tabular}{|c|c|}
\hline $\begin{array}{l}\text { Reconhecimento } \\
\text { Bioquímico }\end{array}$ & Transdutor \\
\hline Anticorpo & $\begin{array}{l}\text { · Detecção eletroquímica } \\
\text { Eletrodos de } \mathrm{Pt}\left(\mathrm{O}_{2} \text { e } \mathrm{H}_{2} \mathrm{O}_{2}\right) \\
\text { Potenciométrico } \\
\text { · Detecção óptica } \\
\text { Fluorescência NADH } \\
\text { Reação de produção de cromóforo } \\
\text { Optodos de pH e Íon-Seletivos } \\
\text { Plasma de superfície } \\
\text { Ressonância } \\
\text { · Detecção por alteração de massa } \\
\text { Piezoelétrico }\end{array}$ \\
\hline Enzima & $\begin{array}{l}\text { - Detecção eletroquímica } \\
\text { Eletrodo de } \mathrm{pH} \\
\text { Sensor a gás }\left(\mathrm{O}_{2}, \mathrm{NH}_{2}, \mathrm{CO}_{2}\right) \\
\text { Eletrodo de } \mathrm{Pt}\left(\mathrm{H}_{2} \mathrm{O}_{2}\right) \\
\text { Eletrodos modificados } \\
\text { FET }^{\mathrm{a}} \\
\text { - Detecção óptica } \\
\text { Fluorescência/Absorção NADH } \\
\text { Reação de produção de cromóforo } \\
\text { Optodos de pH e Íon-Seletivos } \\
\text { - Outros sistemas de detecção } \\
\text { Condutividade } \\
\text { Calorimetria }\end{array}$ \\
\hline
\end{tabular}

\begin{tabular}{ll}
\hline Microorganismos & Amperométrico/Potenciométrico \\
\hline Planta/Tecido Animal & Amperométrico/Potenciométrico \\
\hline
\end{tabular}

${ }^{\mathrm{a}} \mathrm{FET}$ - transistor de efeito de campo; ${ }^{\mathrm{b}} \mathrm{NADH}$ - nicotinamida adenina dinucleotídeo 
das, mínimo preparo de amostra, e possibilidade de automação nas medidas $^{36}$.

O desenvolvimento de métodos empregando biossensores para o monitoramento de resíduos de pesticidas, em matrizes ambientais e de alimentos, é ainda bastante limitado ${ }^{38}$. Em geral, os eletrodos de enzimas mais estudados para análise de pesticidas são aqueles baseados nas enzimas colinesterases $(\mathrm{ChEs})^{39-42}$. Entretanto, para a determinação do pesticida 2,4-D, biossensores à base de anticorpos têm sido desenvolvidos nos últimos anos, com a combinação de técnicas de imunoensaios e de transdutores eletroquímicos ${ }^{32,33}$.

Os ensaios imunoenzimáticos (EIA, "enzyme immunoassay”) surgiram na década de 60 para a identificação e localização de antígenos em preparações histológicas ${ }^{43,44}$, tendo sido a sua utilidade posteriormente reconhecida em outros campos distintos, incluindo as análises de amostras ambientais envolvendo resíduos de contaminantes orgânicos ${ }^{45-47}$. Esta foi a gênese do desenvolvimento de inúmeros ensaios imunológicos (principalmente EIA) para uma grande variedade de pesticidas, aumentando-se espetacularmente sua aceitação a partir de 1988, o que pode ser demonstrado pela extensa literatura sobre esse campo, que aparece em algumas revisões ${ }^{48}$. Atualmente, várias empresas comercializam, em escala mundial, "kits" para a análise de pesticidas baseados nestes métodos, que podem ser utilizados em campo ${ }^{48-51}$. Alguns destes testes já foram, inclusive, adotados como métodos oficiais por parte de agências governamentais, como a EPA (Tabela 4) ${ }^{52}$.

Tabela 4. Métodos imunológicos aprovados pela EPA para análise de pesticidas e de outros contaminantes

\begin{tabular}{ll}
\hline Método & Ensaio Imunológico \\
\hline $4010 \mathrm{~A}$ & Pentaclorofenol \\
4015 & Ácido 2,4-diclorofenoxiacético \\
4020 & PCBs \\
4030 & Hidrocarbonetos de petróleo (em solos) \\
4035 & PAHs (em solos) \\
4040 & Toxafeno (em solos) \\
4041 & Clordane (em solos) \\
4042 & DDT (em solos) \\
4050 & Explosivos TNT (em águas e solos) \\
4051 & Hexaidro-1,3,5-trinitro-1,3,5-triazina (RDX) (em águas \\
& e solos) \\
\hline
\end{tabular}

\section{Análise do 2,4-D}

Para a bioanálise desse herbicida envolvendo técnicas imunoquímicas, diversos tipos de enzimas têm sido utilizados. Entre elas, as enzimas oxidases (OxE), as tirosinases (TyrE) e as acetilcolinesterases (AChE). No caso dos biossensores, seu princípio de funcionamento baseia-se, em geral, em reações imunoenzimáticas que são monitoradas amperometricamente.

$\mathrm{O}$ uso de moléculas heterofuncionais (aquelas que exibem diferentes sítios de ligação para formação do conjugado) também tem sido explorado no desenvolvimento de imunoensaios. Destaca-se, entre as enzimas mais empregadas, a enzima tirosinase, acoplada ao ácido 2,4-diclorofenoxiacético (2,4-D-Tyr), cuja atividade tem sido monitorada eletroquimicamente ${ }^{53}$. Neste caso, o 2,4-D é o hapteno (espécie molecular não imunogênica que se combina com uma macromolécula imunogênica carregadora, sendo capaz de licitar uma resposta imune específica no hospedeiro) reconhecido por um anticorpo monoclonal, e a tirosina é o substrato do eletrodo. Este é um exemplo clássico de acoplamento de um biossensor eletroquímico, que opera com reações imunoquímicas, e que fornece limites de detecção em nmol L-1 (Figura 3).

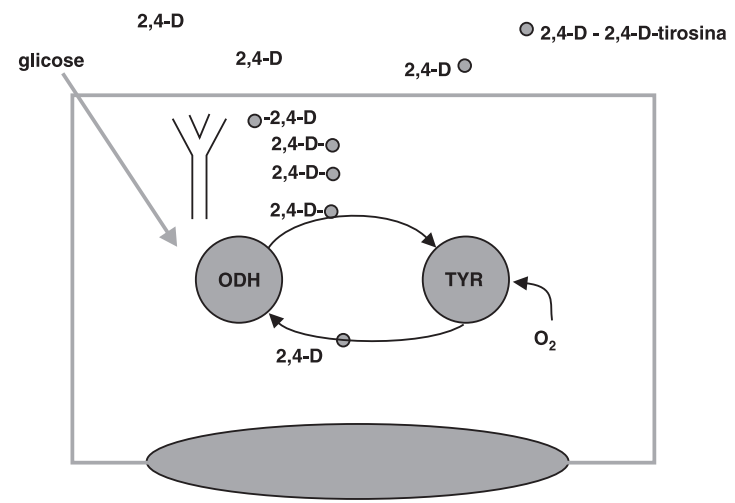

Figura 3. Esquema do imunoensaio enzimático, acoplado a transdutor eletroquímico, à base da enzima bi-funcional do tipo tirosinase, para detecção do pesticida 2,4-D. $Y=$ anticorpo monoclonal. $O$ acoplamento, por ligação covalente do anticorpo com o analito marcado enzimaticamente (2,4-D-tirosina, que funciona, no caso, como antígeno), vai gerar uma reação oxigênio-dependente, que pode ser monitorada por ação simultânea das enzimas tirosinase (Tyr) ou oxigênio-redutase $(\mathrm{ODH})$, com conseqüente desenvolvimento de uma cor característica, cuja absorbância pode ser medida diretamente na placa do imunoensaio

A análise simultânea dos herbicidas 2,4-D e 2,4,5-T pode ser efetuada mediante imunoensaios específicos, utilizando como sistema transdutor um potenciostato (medidas amperométricas). Medyantseva e seus colaboradores ${ }^{54}$ utilizaram como enzimas imobilizadas as acetilcolinesterases, sendo que o princípio analítico foi baseado na inibição enzimática frente aos pesticidas. Faixas de detecção na ordem de $10^{-7}$ a $10^{-11} \mathrm{molL}^{-1}$ foram obtidas. Essa mesma classe de enzimas foi explorada na construção de um imunossensor descartável ${ }^{55}$, do tipo multicanal, usando um anticorpo monoclonal e um conjugado 2,4-DAChE. O método mostrou-se sensível na ordem de partes por milhão, e foi aplicado à análise de amostras de água.

Kalab e Skládal ${ }^{56}$ descreveram a utilização de imunossensores baseados em anticorpos monoclonais para análise do herbicida em amostras de água $^{56}$ e de alimentos ${ }^{57}$. O biossensor consistiu de um eletrodo tri-canal, construído em base de cerâmica mediante a técnica de impressão em tela ("screen-printing"), sendo que o eletrodo de trabalho era de grafite quimicamente modificado, contendo a enzima imobilizada. O limite de detecção foi próximo a $0,1 \mu \mathrm{g} \mathrm{L}^{-1}$. Diferentes enzimas podem, também, ser imobilizadas em um sensor adequado (em geral, têm-se usado os biossensores amperométricos), sendo que cada enzima é seletiva para um único composto ou uma classe de pesticidas ${ }^{58}$.

A enzima fosfatase alcalina foi também utilizada para o preparo de conjugados, tanto para aplicação direta em imunoensaios do tipo ELISA ("enzyme-linked immunosorbent assay") ${ }^{59}$, quanto na obtenção de sensores eletroquímicos ${ }^{60,61}$. Alguns trabalhos envolvendo ELISA tiveram como objetivo verificar o efeito de matriz, quando o método foi empregado na análise de amostras vegetais ${ }^{59,62}$. Os autores observaram que, de modo geral, o efeito de matriz foi fortemente reduzido quando os extratos vegetais obtidos foram previamente diluídos no próprio tampão do ensaio.

Como já mencionado, a maioria dos trabalhos descreve a utilização de EIA's com transdução eletroquímica. Contudo, foram descritos também sistemas envolvendo EIA's e biossensores, que incluem detecção final por fluorescência ${ }^{63-65}$, fibra óptica ${ }^{66}$, espectrometria de massas $^{67}$, detector piezoelétrico ${ }^{68,69}$, quimiluminescência ${ }^{70}$ e transis- 
tor de efeito de campo ${ }^{71}$. Como elementos de bio-reconhecimento, as enzimas mais utilizadas foram as oxidases, imobilizadas de formas variadas ${ }^{72-77}$.

Apesar das elevadas sensibilidade e seletividade dos métodos bioanalíticos, há ainda grandes inconvenientes, que os tornam inadequados para serem considerados métodos oficiais de análise, em substituição aos métodos cromatográficos. Estes inconvenientes estão relacionados à falta de estabilidade da maioria dos organismos utilizados como elementos de bio-reconhecimento, uma vez que se tratam de moléculas biológicas e que, entre outras coisas, comprometem a reprodutibilidade das determinações ao longo do tempo. Entretanto, vantagens como facilidade de operação, sensibilidade e custo relativamente baixo tornam as técnicas analíticas empregando EIA's e biossensores extremamente atrativas, sobretudo quando se deseja efetuar um "screening", antes da análise cromatográfica.

\section{CONCLUSÕES}

Embora o herbicida 2,4-D venha sendo usado e analisado já há bastante tempo, o número de métodos que surgem para o composto e seu principal produto de degradação ainda não resultou no aparecimento de um método que reúna todas as vantagens para a análise destes compostos em amostras de solo e água. No entanto, vários avanços têm sido obtidos, principalmente no campo do reconhecimento molecular e biomolecular. No caso da cromatografia gasosa, poucas novidades têm surgido, principalmente em função da limitação causada pela necessidade de derivação do composto. Em contrapartida, o uso de método "on-line" e o desenvolvimento de novos materiais usados na extração em fase sólida têm favorecido o uso da cromatografia líquida para a análise destes compostos.

Utilizam-se, ainda, técnicas bioanalíticas que apresentam as vantagens de grande seletividade e possibilidade de desenvolvimento de "kits" que podem ser usados in loco. Entretanto, estas técnicas possuem como desvantagens o uso de substratos biológicos que podem apresentar baixa estabilidade, resultando na baixa repetitividade dos sinais analíticos para longos intervalos de análise.

\section{REFERÊNCIAS}

1. Rodrigues, M. V. N.; Serra, G. E.; Pesticidas R. Téc. Cient. 1996, 6, 99.

2. Vieira, E. M.; Prado, A. G. S.; Landgraf, M. D.; Rezende, M. O. de O.; Quim. Nova 1999, 22, 305.

3. Prado, A. G. S.; Vieira, E. M.; An. Assoc. Bras. Quim. 1998, 47, 239.

4. http://ww.anvisa.gov.br/alimentos/tox/mono/d27.htm, acessada em Outubro 2001.

5. Kamrin, M. A.; Pesticides Profile: Toxicity, Environmental Impact, and Fate, Lewis: New York, 1999.

6. http://www.24d.org/, acessada em Novembro 2000.

7. Tadeo, J. L.; Sanchez-Brunete, C.; Perez, R. A.; Fernandez, M. D.; J. Chromatogr., A 2000, 882, 175.

8. Klamp, S.; GIT. Fachz. Lab. 1993, 37, 845.

9. Khomutov, S. M.; Zherdev, A. V.; Dzantiev, B. B.; Reshetilov, A. N.; Anal. Lett. 1994, 27, 2983.

10. Eash, D. T.; Bushway, R. J.; J. Chromatogr., A 2000, 880, 281.

11. Sanchez-Brunete, C.; Garcia-Valcarcel, A. I.; Tadeo, J. L.; J. Chromatogr., A 1994, 675, 213.

12. Coquart, V.; Hennion, M. C.; Sci. Total Environ. 1993, 132, 349.

13. Santos, T. C. R.; Rocha, J. C.; Barceló, D.; J. Chromatogr., A 2000, 879, 3.

14. Amarante Jr., O. P. de; Brito, N. M.; Santos, T. C. R. dos; Ribeiro, M. L.; Talanta, no prelo.

15. Sanchez-Brunete, C.; García-Valcárcel, A. I.; Tadeo, J. L.; J. Chromatogr., A 1994, 675, 213.

16. Hong, M. K.; Kim, M. C.; Smith, A. E.; J. AOAC Int. 1996, 79, 998.

17. Reeve, R. N.; Barnei, J. D.; Environmental Analysis, ACOL: Chichester, 1996.

18. Morrissey, M. A.; Hill, H. H.; J. Chromatogr. Sci. 1989, 27, 529.

19. Craston, D. H.; Saeed, M.; J. Chromatogr., A 1998, 827, 1.

20. Di Corcia, A.; Marchetti, M.; Anal. Chem. 1991, 63, 580.
21. Di Corcia, A.; Marchetti, M.; Environ. Sci. Technol. 1992, 26, 66.

22. Mattina, M. J. I.; J. Chromatogr. 1991, 542, 385.

23. Coquart, V.; Hennion, M. C.; Sci. Total Environ. 1993, 132, 349.

24. Hamann, R.; Kettrup, A.; Chemosphere 1987, 16, 527.

25. Farran, A.; Cortina, J. L.; Anal. Chim. Acta 1990, 234, 119.

26. Hutta, M.; Kaniansky, D.; Kovalcíková, E.; Marák, J.; Chalányová, M.; Madajová, V.; Simunicová, E.; J. Chromatogr., A 1995, 689, 123.

27. Chaudhary, A. J.; Grimes, S. M.; Mukhtar-ul-Hassan; Chemosphere 2001, 44, 1223.

28. Chu, W.; Chemosphere 2001, 44, 935.

29. Yan, M.; Kapua, A.; Anal. Chim. Acta 2001, 435, 163.

30. Baggiani, C.; Giraudi, G.; Giovannoli, C.; Trotta, F.; Vanni, A.; J. Chromatogr., A 2000, 883, 119.

31. Hall, E. A. H.; Biosensors., Open University Press: Buckingham, 1990.

32. Ho, M. Y. K.; Rechnitz, G. A. Em Immunochemical Assays and Biosensor Technology for the 1990s; Nakamura, R. M.; Kasahara, Y.; Rechnitz, G. A., eds.; American Society for Microbiology: Washington, DC, 1992.

33. Coulet, P. R. Em Advances in Biosensors; Turner, A. P. F., ed.; Jai Press: London, 1992, v. 2.

34. Turner, A. P. F.; Karube, I.; Wilson, G. S.; Biosensors. Fundamentals and Applications, Oxford University Press: New York, 1987.

35. Cass, A. E. G.; Davis, G.; Francis, G. D.; Hill, H. A. O.; Aston, W. J.; Higgins, I. J.; Plotkin, E. V.; Scott, L. D. L.; Turner, A. P. F.; Anal. Chem. 1984, 56, 667.

36. Skládal, P.; Food Technol. Biotechnol. 1996, 34, 43.

37. Buerk, D. G.; Biosensors: Theory and Applications, Technomic Publishing: Switzerland, 1993.

38. La Rosa, C.; Pariente, F.; Hernandez, L.; Lorenzo, E.; Anal. Chim. Acta 1995, 308, 129.

39. Skládal, P.; Anal. Chim. Acta 1991, 252, 11.

40. Skládal, P.; Nunes, G. S.; Yamanaka, H.; Ribeiro, M. L.; Electroanalysis 1997, 9, 1083.

41. Nunes, G. S.; Skládal, P.; Yamanaka, H.; Barceló, D.; Anal. Chim. Acta 1998, 362, 59 .

42. Nunes, G. S.; Barceló, D.; Grabaric, B. S.; Díaz-Cruz, J. M.; Ribeiro, M. L.; Anal. Chim. Acta 1999, 399, 37.

43. Nakane, P. K.; Pierce, G. B.; J. Histochem. Cytochem. 1966, 14, 929.

44. Nakane, P. K.; Pierce, G. B.; J. Cell Biol. 1967, 33, 307.

45. Tijssen, P.; Kurstak, E. Em Viral Immunodiagnosis; Kurstak, E.; Morisset, R., eds.; Academic Press: New York, 1974.

46. Ercegovich, C. D. Em Analysis of Pesticide Residues: Immunological Techniques; Nelson, J. O.; Karu, A. E.; Wong, R.B., eds.; American Chemical Society: Washington, DC, 1991.

47. Hammock, B. D.; Mumma, R. O. Em Recent Advances in Pesticide Analytical Methodology; Harvey, J.; Zweig, Z., eds.; American Chemical Society: Washington, DC, 1980.

48. Meulenberg, E. P.; Mulder, W. H.; Stoks, P. G.; Environ. Sci. Technol. 1995, $29,553$.

49. Emon, J. M. van; Gerlach, C. L.; Environ. Sci. Technol. 1995, 29, A312.

50. Barceló, D.; Hennion, M.C., eds.; Techniques and Instrumentation in Analytical Chemistry, Elsevier: Amsterdam, 1997.

51. Gee, S. J.; Hammock, B. D.; van Emon, J. M.; A User's Guide to Environmental Immunochemical Analysis, EPA/540/R-94/509, March, 1994.

52. Nunes, G. S.; Toscano, I. A.; Barceló, D.; Trends Anal. Chem. 1998, 17, 79.

53. Bier, F. F.; Ehrentreich-Förster, E.; Dölling, R.; Eremenko, A. V.; Scheller, F. W.; Anal. Chim. Acta 1997, 344, 119.

54. Medyantseva, E. P.; Vertlib, M. G.; Kutyreva, M. P.; Khaldeeva, E. I.; Budnikov, G. K.; Eremin, S. A.; Anal. Chim. Acta 1997, 347, 71.

55. Kalab, T.; Skládal, P.; Electroanalysis 1997, 9, 293.

56. Kalab, T.; Skládal, P.; Anal. Chim. Acta 1995, 361, 73.

57. Kalab, T.; Skládal, P.; Anal. Chim. Acta 1995, 304, 361.

58. Wang, J.; Nascimento, V. B.; Kane, S. A.; Rogers, K.; Smyth, M. R.; Angnes, L.; Talanta 1996, 43, 1903.

59. Richman, S. J.; Karthikeyan, S.; Bennet, D. A.; Chung, A. C.; Lee, S. M.; J. Agric. Food Chem. 1996, 44, 2924.

60. Wilmer, M.; Trau, D.; Renneberg, R.; Spener, F.; Anal. Lett. 1997, 30, 515.

61. Bauer, C. G.; Eremenko, A. V.; Ehrentreich-Förster, E.; Bier, F. F.; Makower, A.; Halsall, H. B.; Heineman, W. R.; Scheller, F. W.; Anal. Chem. 1996, 68, 2453.

62. Morita, H.; Maehara, T.; Ushiyama, M.; Shokuhin-Eiseigaku-Zasshi 1993, $34,411$.

63. Rogers, K. R.; Kohl, S. D.; Riddick, L. A.; Glass, T.; Analyst 1997, 122, 1107.

64. Matveeva, E. G.; Aguilar-Caballos, M. P.; Eremin, S. A.; Gomez-Hens, A.; Perez-Bendito, D.; Analyst 1997, 122, 863. 
65. Lukin, Y. V.; Dokuchaev, I. M.; Polyak, I. M.; Eremin, S. A.; Anal. Lett. 1994, 27, 2973.

66. Mosiello, L.; Nencini, L.; Segre, L.; Spano, M.; Sens. Actuators, B 1997, $39,353$.

67. Canosa, D.; Daniel, R.; Barceló, D.; Gelpi, E.; Le-Goffic, F.; Abian, J.; Int. J. Mass Spectrom. 1997, 160, 395.

68. Horacek, J.; Skládal, P.; Anal. Chim. Acta 1997, 347, 43.

69. Minunni, M.; Skládal, P.; Mascini, M.; Anal. Lett. 1994, 27, 1475.

70. Dzgoev, A.; Mecklenburg, M.; Larsson, P. O.; Danielsson, B.; Anal. Chem. 1996, 68, 3364.

71. Khomutov, S. M.; Zherdev, A. V.; Dzantiev, B. B.; Reshetilov, A. N.; Anal. Lett. 1994, 27, 2983.
72. Bier, F. F.; Ehrentreich-Foerster, E.; Bauer, C. G.; Scheller, F. W.; Frezenius' J. Anal. Chem. 1996, 354, 861.

73. Dzantiev, B. B.; Zherdev, A. V.; Yulaev, M. F.; Sitdykov, R. A.; Dmitrieva, N. M.; Moreva, I. Y.; Biosens. Bioelectron. 1996, 11, 179.

74. Matuszczyk, G.; Knopp, D.; Niessner, R.; Frezenius' J. Anal. Chem. 1996, $354,41$.

75. Yulaev, M. F.; Sitdykov, R. A.; Dmitrieva, N. M.; Dzantiev, B. B.; Zherdev, A. V.; Askarov, K. A.; Zh. Anal. Khim. 1995, 50, 211.

76. Gu, Y.; Knaebel, D. B.; Korus, R. A.; Crawford, R. L.; Environ. Sci. Technol. 1995, 29, 1622.

77. Fleeker, J.; J. Assoc. Off. Anal. Chem. 1987, 70, 874. 